\title{
Op weg naar een economische organisatie- theorie: de transactiekostenbenadering
}

\section{Inleiding}

In de economische theorie kan men thans twee nauw aan elkaar verwante stromingen onderscheiden, die men kan beschouwen als aanzetten op weg naar een economische organisatietheorie. Het gaat om de agency-theorie en de transactiekostenbenadering. De agency-theorie werd in een eerder artikel in het MAB besproken. In dit artikel staat de transactiekostenbenadering centraal. Het artikel over agency-theorie behoeft u niet te hebben gelezen om toch de rode draad van dit artikel te kunnen volgen.

Waarover gaat het in de transactiekostenbenadering? Het gaat in de transactiekostenbenadering om de vraag waarom bepaalde organisatievormen zijn ontstaan en onder welke omstandigheden die organisatievormen kunnen overleven. Neem als voorbeeld de reeds in 1937 door Goase gestelde vraag: 'Waarom bestaan er ondernemingen?' Of wat op hetzelfde neerkomt: 'Waarom worden niet alle economische beslissingen gecoördineerd door middel van het marktmechanisme?'

Economische beslissingen kunnen op elkaar worden afgestemd door middel van het marktmechanisme óf door middel van een 'managerial hierarchy'. Markt en hiërarchie zijn in deze visie twee alternatieve coördinatie-mechanismen. Coördinatie van economische beslissingen via de markt brengt transactiekosten met zich mee. Coördinatie door middel van een management-hiërarchie brengt interne coördinatiekosten met zich mee. Coördinatie door middel van de markt wordt vervangen door coördinatie binnen de onderneming als de interne coördinatiekosten lager zijn dan de transactiekosten. Deze door Coase gegeven verklaring voor het ontstaan van ondernemingen bergt echter het gevaar in zich van een tautologie: Waar een onderneming is ontstaan zijn blijkbaar de transactiekosten hoger geweest dan de interne coördinatiekosten nu zijn. Zo heeft het verschijnsel, dat men wil verklaren, alleen een andere naam gekregen maar een echte theorie met toetsbare hypotheses is het nog niet.

Het komt er dus op aan om van te voren te kunnen zeggen in welke situaties de transactiekosten hoog zijn en in welke situaties laag. Als dan vervolgens blijkt dat in situaties waarin de transactiekosten hoog zijn inderdaad ondernemingen ontstaan en in andere situaties niet, dan is men inderdaad op weg naar een economische organisatietheorie. Oliver Williamson heeft in 
een zeer omvangrijk oeuvre dit pad reeds grotendeels geëffend. Dit artikel steunt dan ook voor een belangrijk deel op het werk van Williamson, in het bijzonder op het in 1975 verschenen boek 'Markets and Hierarchies' en het in 1986 verschenen boek 'The Economic Institutions of Capitalism'.

Andere benamingen voor de transactiekostenbenadering zijn: het 'markten en hiërarchieën-paradigma', het 'organizational failures framework', het 'market failures framework' en de 'nieuwe institutionele economie'. De benaming van 'transactiekostenbenadering' geeft een wat eenzijdig beeld omdat interne coördinatiekosten eveneens een rol spelen. De benaming, 'markten en hiërarchieën-paradigma' geeft eigenlijk beter aan waar het eigenlijk om gaat.

Dit artikel is verder opgebouwd als volgt. Eerst worden de basisveronderstellingen van de transactiekostenbenadering uiteengezet (par. 2). Vervolgens komen twee verschillende toepassingen aan de orde, namelijk verticale integratie (par. 3) en interne organisatie binnen de onderneming (par. 4). Door de keuze van deze twee toepassingen wordt meteen duidelijk dat de transactiekostenbenadering zowel voor de interne als voor de externe organisatiekunde nieuwe gezichtspunten oplevert. Tot slot worden enkele in het oog springende verschillen en overeenkomsten tussen de theorie van principaal en agent, de positieve agency-theorie en de transactiekostenbenadering besproken (par. 5).

\section{Basisveronderstellingen}

Wat zijn eigenlijk transactiekosten? Transactiekosten worden wel onderscheiden in drie componenten: ten eerste de kosten verbonden aan het zoeken van een tegenpartij (voor iemand die zijn huis wil verkopen onder andere de kosten van advertenties waarin het huis te koop wordt aangeboden én een deel van de makelaarsprovisie); ten tweede de kosten verbonden aan het opstellen van het contract (het andere deel van de makelaarsprovisie en de kosten van de notaris); en ten derde de kosten die partijen maken om te voorkomen dat er contractbreuk wordt gepleegd (bijvoorbeeld de kosten verbonden aan het stellen van een bankgarantie).

In welke situaties mag men hoge transactiekosten verwachten?

Het antwoord op die vraag zoekt Williamson (1986) in de eigenschappen van menselijke actoren en in kenmerken van transacties.

\section{Eigenschappen van menselijke actoren}

Twee menselijke eigenschappen bepalen volgens Williamson het ontstaan van transactiekosten: begrensde rationaliteit en opportunisme.

Begrensde rationaliteit betekent dat mensen wel rationeel willen handelen maar daartoe slechts in beperkte mate in staat zijn. 'Human behavior is intendedly rational but only limitedly so' is een veel geciteerde uitspraak van Simon (1961). Williamson volgt hier Cyert en March (1963) met wie hij eerder nauw heeft samengewerkt. 
Opportunisme wordt door Williamson omschreven als 'self-interest seeking with guile'. Mensen streven dus hun eigenbelang na en schrikken daarbij niet terug voor oneerlijk gedrag, zoals liegen, stelen en bedrog. Ook meer subtiele vormen van oneerlijkheid, zoals het vertellen van de halve waarheid of het geven van een te optimistische schets van de eigenschappen van een nieuw produkt zijn voorbeelden van opportunistisch gedrag. Veel mensen reageren op het begrip opportunisme met een gevoel van ergernis. Er zijn toch ook eerlijke mensen? Voor de transactiekostenbenadering is het voldoende om te veronderstellen dat sommige mensen soms oneerlijk zijn én dat ex ante moeilijk is vast te stellen wie wanneer oneerlijk gedrag zal vertonen. $\mathrm{Bij}$ het opstellen van contracten moet men met mogelijk opportunistisch gedrag rekening houden, omdat men tevoren niet met zekerheid het al of niet betrouwbaar zijn van de tegenpartij kan voorspellen.

De menselijke actor uit de transactiekostenbenadering wijkt dus op twee punten af van de homo economicus uit de neoklassieke micro-economische theorie: hij is minder competent als rekenaar en hij is mogelijk niet altijd voor honderd procent betrouwbaar.

\section{Kenmerken van transacties}

Begrensde rationaliteit en opportunistisch gedrag behoeven niet in iedere situatie te leiden tot hoge transactiekosten. Dat hangt samen met drie door Williamson onderscheiden kenmerken van transacties:

a De specificiteit van activa of anders gezegd de mate warin transacties worden ondersteund door transactie-specifieke investeringen;

b De onzekerheid waaraan transacties onderhevig zijn;

c De frequentie van de transacties.

\section{ad a: De specificiteit van activa}

Sommige transacties worden in sterke mate ondersteund door transactiespecifieke investeringen, andere transacties in het geheel niet. Om duidelijk te maken wat bedoeld wordt met transactie-specifieke investeringen geef ik het door Klein, Crawford en Alchian (1978) uitgewerkte voorbeeld van de relatie tussen een dagbladuitgever en een drukker. Dit voorbeeld luidt als volgt.

Drukker A heeft een drukpers gekocht om het dagblad van uitgever B te drukken. De vaste kosten, inclusief afschrijving voor de drukpers bedragen $f 4000$, - per dag. De hoogte van deze vaste kosten is niet afhankelijk van de vraag of de drukpers al dan niet in bedrijf is. Daarnaast zijn er variabele kosten van $f 1500$, - per dag voor iedere dag dat de pers in bedrijf is.

Dagbladuitgever B laat zijn dagblad drukken door A en betaalt daarvoor $f 5500$,- per dag. De pers van $\mathrm{A}$ is alleen geschikt voor het drukken van dagbladen. Uitgever $B$ is de enige dagbladuitgever in de regio. De pers van A heeft dus geen alternatieve aanwendingsmogelijkheden. Als A de pers zou verkopen, dan moet de pers worden gedemonteerd, verplaatst en elders weer worden gemonteerd. De geschatte verkoopprijs van de pers zou overeenkomen met $f 1000$,- per dag (dat wil zeggen de contante waarde van een inkomstenstroom van $f 1000$,- per dag komt overeen met de 
geschatte verkoopprijs). De drukpers van drukker A is typisch een transactie-specifieke investering: hij is door $\mathrm{A}$ aangekocht met het oog op de transactie met $B$ en heeft in de beste alternatieve aanwending een veel lagere opbrengstwaartde. Klein, Crawford en Alchian introduceren nu het begrip 'appropriable quasi-rent', dat is de contante waarde van de huidige inkomstenstroom verminderd met de contante waarde van de inkomstenstroom bij de beste alternatieve aanwending. In dit voorbeeld is de appropriable quasi-rent gelijk aan de contante waarde van $f 5500,--f 1500$, - $f 1000,-=f 3000,-$ per dag (de huidige inkomstenstroom is $f 5500,--$ $f 1500$, - per dag en de beste alternatieve aanwending is equivalent met een inkomstenstroom van $f 1000,-$ per dag).

Uitgever B kan nu proberen een deel van deze appropriable quasi-rent naar zich toe te halen door aan te dringen op prijsverlaging. Drukker A heeft daartegen geen verweer. Pas als de prijs lager wordt dan $f 1000$,- per dag zal A zich effectief kunnen verzetten.

Kunnen A en B niet een contract afsluiten met een looptijd gelijk aan de levensduur van de pers vóórdat A de pers bestelt? Dan zou A gevrijwaard zijn voor opportunistisch gedrag van B. Zo'n lange-termijn contract kan echter op allerlei moeilijkheden stuiten. Stel dat en A en B een contract sluiten voor een periode van 10 jaar tegen een vaste prijs van $f 5500$, - per dag. Stel nu dat de inkomsten van B tegenvallen, zodat B failliet gaat als hij $f 5500,-$ per dag moet blijven betalen. Stel echter dat B net kan blijven bestaan als hij $f 4800$,- per dag moet betalen. B legt deze situatie uit aan A. Zou A dan niet genegen zijn de prijs te verlagen tot $f 4800$,- per dag (als $\mathrm{B}$ failliet gaat vallen zijn inkomsten terug tot $f 1000,-$ per dag)? Als A er maar van overtuigd is dat de beweringen van B waar zijn, zal hij de prijs inderdaad verlagen tot $f 4800$,- per dag. Maar dit opent voor B mogelijkheden voor opportunistisch gedrag, ondanks het lange-termijn contract.

De les uit dit voorbeeld is deze: hoe meer de transacties tussen twee partijen worden ondersteund door transactie-specifieke investeringen, des te groter zijn de mogelijkheden voor opportunistisch gedrag.

In 'Markets and Hierarchies' werd het begip opportunisme vooral gekoppeld aan 'small numbers bargaining'. Opportunistisch gedrag van één van beide contractpartijen kan gemakkelijk worden afgestraft als het aantal marktpartijen groot is (na eenmaal te zijn bedrogen ga je dan eenvoudig met een ander in zee). Is er echter sprake van small numbers, dan wordt opportunisme wel een probleem. In het voorbeeld van de drukker en de dagbladuitgever was er sprake van één aanbieder en één vrager dat wil zeggen small numbers in extreme vorm. Door het begrip opportunisme te koppelen aan 'specificiteit van activa' wordt de relatie tussen opportunisme en small numbers nog wat scherper geformuleerd.

\section{ad b: De onzekerheid, waaraan transacties onderhevig zijn}

De onzekerheid waaraan transacties onderhevig zijn bepaalt ook mede de hoogte van de transactiekosten. Om dit te illustreren, dient het volgende voorbeeld. Koper $\mathrm{C}$ overweegt bij producent $\mathrm{D}$ een technologisch zeer gecompliceerd produkt te bestellen, dat D nog moet ontwerpen. Stel, dat 
de kostprijs van het produkt op het moment waarop C en D onderhandelen nog zeer onzeker is. Eén mogelijkheid is, dat producent $D$ het risico draagt. $\mathrm{D}$ zal dan de verwachte kostprijs verhogen met een risicopremie. Stel, dat koper $\mathrm{C}$ deze risicopremie te hoog vindt. Als $\mathrm{C}$ de risicopremie te hoog vindt betekent dat, dat hij liever het risico zelf draagt dan dat hij de risicopremie betaalt. Koper $\mathrm{C}$ kan het risico dragen als $\mathrm{C}$ en $\mathrm{D}$ werken met een 'open begroting': D registreert de kosten en C betaalt de gemaakte kosten. Het probleem met zo'n contract is, dat D nu geen enkele prikkel meer heeft om efficiënt te werken. D kan zelfs in de verleiding komen om meer kosten aan het project ten behoeve van $\mathrm{C}$ toe te rekenen dan eigenlijk gerechtvaardigd is. Zo'n contract moet van te voren dus zeer precies worden gespecificeerd (er moeten onder andere verdeelsleutels ten aanzien van de algemene kosten in worden opgenomen), terwijl tevens de naleving van het contract door of namens $\mathrm{C}$ (bijvoorbeeld door een onafhankelijke accountant) moet worden gecontroleerd. Dit brengt hoge transactiekosten met zich mee.

ad c: De frequentie van de transacties

Hoe vaker een transactie wordt gesloten, des te hoger zijn op jaarbasis de transactiekosten. Dit punt behoeft verder geen toelichting.

\section{Verticale integratie}

$\mathrm{Nu}$ duidelijk is geworden in welke situaties Williamson hoge transactiekosten verwacht (dat zijn situaties die gekenmerkt worden door hoge asset specificity, grote onzekerheid en hoge frequentie) wordt het tijd om enkele toepassingen te bespreken. Wij kiezen daarvoor verticale integratie. Dat is een sprekend voorbeeld van het vervangen van markttransacties door interne coördinatie binnen de onderneming.

In welke gevallen zal er verticale integratie optreden? Vroeger zocht men de verklaring voor verticale integratie vooral in de technologie. Het klassieke voorbeeld is de fabricage van ijzer en staal. Door een hoogoven en een staalfabriek zij aan zij te bouwen kunnen belangrijke energiebesparingen worden gerealiseerd. In de praktijk leidt dit tot verticale integratie: de hoogoven en de staalfabriek behoren tot één onderneming.

In de optiek van de transactiekostenbenadering is deze verklaring echter onvoldoende. Men zou zich kunnen voorstellen, dat de fabricage van ijzer en de fabricage van staal door twee afzonderlijke ondernemingen geschiedt. Deze twee ondernemingen moeten dan wel hun hoogoven respectievelijk staalfabriek naast elkaar bouwen om de energiebesparing te kunnen realiseren. Het hoogovenbedrijf en de staalfabriek zouden dan een contract voor de levering van vloeibaar ijzer moeten sluiten. Er is dan sprake van een zeer grote specificiteit van activa: het hoogovenbedrijf heeft maar één klant en de staalfabriek heeft voor de belangrijkste input (vloeibaar ijzer) maar één leverancier. Net als de uitgever en de drukker in het eerder gegeven voorbeeld zijn beide partijen 'elkaars gevangenen'. Als beide partijen in zo'n situatie vóórdat zij tot investeren overgaan proberen een lange- 
termijn contract met elkaar te sluiten, stuiten zij op het probleem van begrensde rationaliteit. Het is zeer moeilijk van te voren alle veranderingen, die zich over een periode van 10 of 20 jaar kunnen voordoen te voorzien en daarmee in het contract nu al rekening te houden. Hoe groter de onzekerheid en de complexiteit van de omgeving, des te moeilijker (en dus kostbaarder) dat is. Beide partijen kunnen dat probleem proberen te omzeilen door een korte-termijn contract af te sluiten. Zodra zich onverwachte omstandigheden voordoen kan men daarmee bij het opstellen van het volgende korte-termijn contract rekening houden. Het probleem met zo'n reeks korte-termijn contracten is gelegen in de hoge kosten van heronderhandeling. Daarbij moet men vooral ook denken aan de produktie-onderbrekingen, die door een van beide partijen als dreigement kunnen worden gehanteerd (vergelijkbaar met stakingen).

Het bovenstaande voorbeeld van de hoogoven en de staalfabriek is nogal triviaal. Het leent zich ook niet voor empirische toetsing.

Tussen bedrijfstakken bestaan verschillen in de mate waarin men voorwaarts verticaal integreert in de distributie. Deze verschillen gebruikt Daems (1982) om de transactiekostenbenadering te toetsen. Hij baseert zijn empirisch onderzoek op Amerikaanse gegevens. Centraal in zijn onderzoek staat het begrip transactie-specifieke investeringen. In welke mate worden transacties tussen producenten en distributiekanalen ondersteund door transactie-specifieke investeringen? Daems ziet onder meer in brand name capital, en investments in product specific selling services voorbeelden van transactie-specifieke investeringen. Brand name capital bestaat uit de geaccumuleerde investeringen in reclame. Hoe hoger de investeringen in merknaamreputatie des te kwetsbaarder wordt de fabrikant voor opportunistisch gedrag door de distributiekanalen: een zorgeloze behandeling kan leiden tot kwaliteitsverlies of tot een situatie waarin het produkt na een reclamecampagne niet overal verkrijgbaar is.

In het geval van investments in product-specific selling services zijn de mogelijkheden voor opportunistisch gedrag omgekeerd. Hier is het het distributiekanaal, dat moet investeren in know-how teneinde de produkten van een bepaalde leverancier te kunnen verkopen. Daarmee stelt hij zich bloot aan opportunistisch gedrag door de leverancier.

Omdat de aanwezigheid van brand-name capital niet direct is te meten gebruikt Daems in plaats daarvan de reclame-uitgaven als percentage van de omzet. Evenzo gebruikt hij de uitgaven voor Research en Development door de producent als benadering voor de aanwezigheid van product specific selling services. Beide variabelen (reclame-uitgaven: omzet en $R$ en $D$ uitgaven: omzet) blijken positief gecorreleerd te zijn met de mate van verticale integratie.

Is hiermee nu een empirische toets van de transactiekostenbenadering gevonden? Tot op zekere hoogte wel, maar er blijft toch een probleem. Dat is dat men twee dingen tegelijkertijd toetst: de transactiekostenbenadering zelf én de redenering die ertoe leidt dat uiteindelijk de variabelen reclame- 
uitgaven: omzet en $\mathrm{R}$ en D-uitgaven: omzet, worden gecorreleerd met de omzet. Daarbij kan men zich ook afvragen of de reclame-uitgaven als percentage van de omzet wel een goede maatstaf zijn voor de aanwezigheid van brand name capital. Geld uitgeven aan reclame is alleen dan een goede maatstaf voor de aanwezigheid van brand name capital als alle reclameuitgaven van alle ondernemingen even effectief zijn. Evenzo kan men ook vraagtekens plaatsen bij het gebruik van de $R$ en $D$-uitgaven als percentage van de omzet als indicatie voor de aanwezigheid van product specific selling services. Andere onderzoekers, bijvoorbeeld Levy (1985) en MacDonald (1985) hebben soortgelijke toetsen uitgevoerd. Ook zij toetsen eigenlijk twee dingen tegelijkertijd.

Andere manieren om een empirische ondersteuning voor de transactiekostenverklaring te verkrijgen zijn het uitvoeren van een case-study van een onderneming (Klein, Crawford en Alchian, 1978) of van een bedrijfstak (Mariotti en Cainarca, 1986), of het interpreteren van beschikbaar historisch onderzoek (Chandler, 1962 en 1977, wordt veelvuldig door Williamson geciteerd).

Behalve voor het verklaren van verticale integratie kan de transactiekostenbenadering ook worden gebruikt voor het verklaren van diversificatie en multinationalisatie (zie bijvoorbeeld Douma, 1985 en Teece, 1982 en 1986).

Ik wil echter niet de indruk wekken dat de transactiekostenbenadering alleen voor vraagstukken van externe organisatie relevant is. Daarom nu iets over interne organisatie.

\section{Interne organisatie}

De meest belangrijke organisatorische innovatie van deze eeuw is volgens Williamson (1986, p. 279) de ontwikkeling in de jaren twintig van de divisiestructuur. Waarom is de divisiestructuur (verder aan te duiden als M-form, waar M staat voor multidivisiestructuur) zo succesvol gebleken?

Een zeer kleine onderneming kent meestal nauwelijks enige interne structuur. Alle interne coördinatie kan door één persoon worden verricht. Dit is de ondernemer, die de belangrijkste residuele inkomenstrekker is.

Als de onderneming groter wordt, groeit ook de omvang van de interne coördinatie-taak. Daarbij blijkt een functionele indeling gewoonlijk doelmatig. Er ontstaan dan afdelingen voor marketing, produktie, research en development, personeelszaken, financiën, administratie enz. Als de onderneming nu groeit door middel van produktdiversificatie neemt de complexiteit van de interne coördinatie sterk toe. In een functioneel georganiseerde onderneming (verder aan te duiden als $U$-form voor unitary form) stuit men dan op het probleem van begrensde rationaliteit: het topmanagement van zo'n onderneming is niet in staat de zeer talrijke dagelijkse operationele beslissingen effectief te coördineren en tevens aandacht te besteden aan strategische vraagstukken. Managers van de functionele afdelingen krijgen de neiging om het belang van de eigen afdeling te verdedigen en de bijdrage 
van hun eigen activiteit aan de doelstellingen van de onderneming als geheel uit het oog te verliezen. Dit is voor een deel een uiting van opportunisme. Begrensde rationaliteit en opportunisme leiden bij de functioneel georganiseerde, gediversificeerde onderneming tot zeer hoge interne coördinatiekosten. Om dit probleem het hoofd te bieden kan men ondernemingen (profit-centres) binnen de onderneming vormen. Dit leidt tot het ontstaan van dochterondernemingen. In het uiterste geval kan de centrale leiding zich beperken tot de rol van aandeelhouder. Deze organisatievorm, de holding company, (verder aan te duiden als $\mathrm{H}$-form) heeft echter twee belangrijke nadelen. Ten eerste is er het probleem van opportunisme. Omdat de manager van een dochteronderneming niet de residuele inkomenstrekker is, ontstaat er een agency-probleem: is het goede of slechte resultaat van de dochteronderneming te danken respectievelijk te wijten aan zijn inspanning of aan het toeval? Nu de discipline van de vermogensmarkt is weggevallen is er tenminste een beoordelings- en een beloningssysteem nodig. De holding zal in het algemeen niet kunnen toestaan dat de dochterondernemingen zelf eigen vermogen van buiten aantrekken (de holding zou er zijn meerderheid door kunnen verliezen). De dochter zal dan voor de financiering van investeringsprojecten een beroep moeten doen op de holding. Eenvoudige regels, zoals: 'Elke dochter moet haar netto cashflow (dat is cash-flow minus investeringsuitgaven) afstaan aan holding' werken opportunistisch gedrag in de hand. In het onderhavige voorbeeld gaan de dochters met een ruime cash-flow waarschijnlijk te veel investeren.

In de tweede plaats kunnen zich problemen voordoen als de dochters op grote schaal zaken doen met elkaar. Dit brengt als de dochters zich gedragen als onafhankelijke ondernemingen transactiekosten met zich mee, waarvan de hoogte afhankelijk is van de kenmerken van de transacties (specificiteit van activa, onzekerheid en frequentie). Om deze transactiekosten te verlagen moet een andere interne organisatievorm worden gekozen.

De 'M-form' onderneming is een onderneming, waarin de divisies een grote mate van zelfstandigheid bezitten voor wat betreft dagelijkse, operationele beslissingen. Het hoofdkantoor speelt echter een in vergelijking met een $\mathrm{H}$-form onderneming zeer belangrijke rol in het toewijzen van financiële middelen aan de divisies en in het ontwikkelen van een management development programma. Managers van dochterondernemingen worden voortdurend beoordeeld en maken intern carrière. De M-form onderneming kent met andere woorden een interne vermogensmarkt en een interne arbeidsmarkt voor managers.

De M-form onderneming vermijdt door het delegeren van alle operationele beslissingen naar de divisies het probleem van begrensde rationaliteit, waarmee de U-form onderneming worstelt. De M-form onderneming vermijdt door haar interne vermogensmarkt en haar interne arbeidsmarkt voor managers ook het probleem van opportunisme, dat de $\mathrm{H}$-form onderneming kent. De transactiekosten van transacties tussen divisies kunnen worden beperkt door ingrijpen vanuit het hoofdkantoor (bijvoorbeeld door het vaststellen van transfer-prijzen). 
Een divisiestructuur is niet in alle omstandigheden de beste organisatiestructuur. In bepaalde gevallen kan een functionele structuur of een holding-company structuur de voorkeur verdienen.

\section{Slot: transactiekostenbenadering en agency-theorie}

Ik wil dit artikel besluiten met enkele opmerkingen over de overeenkomsten en de verschillen tussen de agency-theory, die in een eerder artikel werd besproken, en de transactiekostenbenadering. Daarbij moet de agencytheorie worden onderscheiden in de theorie van principaal en agent en in de positieve agency-theorie.

De positieve agency-theorie en de transactiekostenbenadering hebben zeer veel gemeen. Beide vragen zij zich af waarom bepaalde organisatievormen zijn ontstaan. Beide gaan zij ervan uit dat er tussen organisatievormen concurrentie bestaat en dat alleen de meest doelmatige organisatievorm overleeft. De overeenkomsten tussen biologische evolutie (Darwin) en de ontwikkeling van organisatievormen is frappant in beide benaderingen. Ik verwacht, dat beide benaderingen op den duur nauwelijks van elkaar zullen zijn te scheiden.

$\mathrm{Nu}$ iets over de theorie van principaal en agent en de transactiekostenbenadering. Net als de transactiekostenbenadering gaat de theorie van principaal en agent uit van mogelijk opportunistisch gedrag van de agent: als de agent zou kunnen beloven een bepaald inspanningsniveau te leveren en als de principaal zou weten dat de agent zich altijd aan zijn belofte houdt, verdwijnt het agency-prowleem. Het verschil tussen de theorie van principaal en agent en de transactiekostenbenadering zit in de veronderstelling ten aanzien van rationaliteit: de theorie van principaal en agent veronderstelt onbegrensde rationaliteit, de transactiekostenbenadering begrensde rationaliteit.

Kijkt men naar de veronderstellingen inzake de eigenschappen van actoren (rationaliteit en opportunisme) dan is een indeling mogelijk in vier categorieën (zie figuur).

\begin{tabular}{|c|l|l|l|}
\cline { 3 - 4 } \multicolumn{2}{c|}{} & \multicolumn{2}{c|}{ Opportunisme } \\
\cline { 3 - 4 } $\begin{array}{l}\text { Ratio- } \\
\text { naliteit }\end{array}$ & Onbegrensd & $\begin{array}{l}\text { Theorie van } \\
\text { principaal en } \\
\text { agent }\end{array}$ & Afwezig \\
\cline { 2 - 4 } & Begrensd & $\begin{array}{l}\text { Capital asset } \\
\text { pricing model } \\
\text { Transactiekosten- } \\
\text { ponadering; } \\
\text { agency-theorie }\end{array}$ & \\
\hline
\end{tabular}


De neo-klassieke micro-economische theorie veronderstelt onbegrensde rationaliteit en afwezigheid van opportunisme. Als voorbeeld is in de figuur genoemd het capital asset pricing model.

Zoals uit het bovenstaande reeds is gebleken zijn de agency-theorie en de transactiekostenbenadering nog volop in ontwikkeling. Van volgroeide en empirisch uitvoerig getoetste theorieën (zoals bijvoorbeeld het CAPM er een is) kan nog niet worden gesproken. Het lijkt echter wel vast te staan dat zowel de agency-theorie als de transactiekostenbenadering belangrijke leerstukken zullen worden, die zowel in de economische theorie als in de organisatiekunde een vaste plaats zullen krijgen.

\section{Literatuur}

Chandler, A. D. (1962): Strategy and Structure, M.I.T. Press, Cambridge, Mass.

Chandler, A. D. (1977): The Visible Hand: The Managerial Revolution in American Business, Harvard University Press, Cambridge, Mass.

Cyert, R. M. en J. G. March (1963): A Behavioral Theory of the Firm, Prentice Hall, Englewood Cliffs, N.J.

Daems, H. (1982): Inter-industry Differences in Forward Vertical Integration by Ownership, Working Paper 1982-1. European Institute for Advanced Studies in Management, Brussel.

Douma, S. W. (1985): Concurrentiestrategieën, een kijkje vanuit de micro-economische theorie, Open Universiteit/Samsom, Alphen a.d. Rijn.

Klein, B., R. G. Crawford en A. A. Alchian (1978): Vertical Integration, Appropriable Rents and the Competitive Contracting Process, Journal of Law and Economics, 21, pag. 297-326.

Levy, D. (1985): The Transaction Cost Approach to Vertical Integration: An Empirical Analysis, Review of Economics and Statistics, 67, pag. 438-445.

MacDonald (1985): Market Exchange or Vertical Integration: An Empirical Analysis, Review of Economics and Statistics, pag. 327-331.

Mariotti, S. en G. C. Cainarca: The Evolution of Transaction Governance in the TextileClothing Industry, Journal of Economic Behavior and Organization, 7, pag. 351-374.

Simon, H. A. (1961): Administrative Behavior, 2nd ed', MacMillan, New York.

Teece, D. J. (1982): Towards an Economic Theory of the Multiproduct Firm, Journal of Economic Behavior and Organization, 3, pag. 39-63.

Teece, D. J. (1986): Transaction Cost Economics and the Multinational Enterprise, Journal of Economic Behavior and Organization, 7, pag. 21-45.

Williamson, O. E. (1975): Markets and Hierarchies: Analysis and Antitrust Implications, The Free Press, New York.

Williamson, O. E. (1986): The Economic Institutions of Capitalism Firms, Markets, Relational Contracting, The Free Press, New York. 